\title{
LEAN MASS IS INVERSELY ASSOCIATED WITH BREAST CANCER, WHILE ABDOMINAL ADIPOSITY AND INSULIN RESISTANCE INCREASES THE CHANCES OF DEVELOPING THE CANCER
}

Jordana C. M. Godinho-Mota1,2, Larissa V. Gonçalves ${ }^{1,2}$, Raquel M. Schincaglia², João F. Mota², Karine A. Martins², Ruffo Freitas-Junior ${ }^{1}$

${ }^{1}$ CORA - Centro Avançado de Diagnóstico da Mama, Hospital das Clínicas, Universidade Federal de Goiás - Goiânia (GO), Brazil. ${ }^{2}$ School of Nutrition, Clinical and Sports Nutrition Research Laboratory (Labince), Universidade Federal de Goiás - Goiânia (GO), Brazil.

Objective: To investigate whether breast cancer is associated with body composition, insulin resistance, and lipid profile. Methodology: This was a case-control study with 175 women recently diagnosed with breast cancer and 299 controls. Body composition was assessed by dual-energy X-ray absorptiometry. Waist circumference (WC) was measured as an indirect cardiometabolic risk factor $(>80 \mathrm{~cm})$. Total cholesterol, high-density lipoprotein (HDL), low-density lipoprotein (LDL), very-low-density lipoprotein (VLDL), triglycerides, fasting blood glucose, glycated hemoglobin and insulin resistance (HOMA-IR<1.65) were assessed in plasma. Logistic regression was adjusted for body mass index (BMI) and age to quantify the association between breast cancer risk and body composition, insulin resistance, dyslipidemias, and abdominal adiposity. Results: The mean age of patients was $52 \pm 11$ years. The case group had low lean mass compared to controls (35.04 \pm 5.09 vs $36.44 \pm 5.95 \mathrm{~kg}, \mathrm{p}=0.02)$, even showing the same BMI (27.21 $\pm 5.27 ;$ vs $27.58 \pm 5.17, \mathrm{p}=0.26)$. Women diagnosed with breast cancer had high concentrations of triglycerides ( $134.07 \pm 67.57$ vs $123.48 \pm 73.75 ; p=0.03$ ). The logistic regression showed that breast cancer was inversely associated with lean mass and low fat mass (OR 0.93; 95\%CI 0.89-0.97 and OR 0.26; 95\%CI 0.13-0.53, respectively). Insulin resistance (OR 2.33; 95\%CI 1.35-4.04) and abdominal obesity (OR 4.18; 95\%CI 1.83-9.57) was positively associated with breast cancer. Conclusions: Lean mass was inversely associated with breast cancer, while abdominal adiposity and insulin resistance increases the chances of developing the cancer. 